\title{
A large-Scale Survey of Current Status of Scientific Research and Innovation Ability Cultivation for Undergraduates
}

Fuling Zhou ( $\nabla$ zhoufuling@whu.edu.cn )

Zhongnan Hospital of Wuhan University

\section{Ping Luo}

Zhongnan Hospital of Wuhan University

\section{Hairong Wang}

Zhongnan Hospital of Wuhan University

\section{Hui Shen}

Zhongnan Hospital of Wuhan University

\section{Yufeng Yuan}

Zhongnan Hospital of Wuhan University

\section{Xian Zhang}

Zhongnan Hospital of Wuhan University

\section{Research Article}

Keywords: medical education, undergraduates, undergraduate tutorial system, opening laboratory, innovation ability

Posted Date: January 31st, 2022

DOI: https://doi.org/10.21203/rs.3.rs-1258089/v1

License: (9) This work is licensed under a Creative Commons Attribution 4.0 International License. Read Full License 


\section{Abstract}

Background: Wuhan University Medical College has implemented the reform of innovative education for undergraduates. This study aims at investigating the practice of the Innovation Education Reform and find out problems to be improved.

Methods: Total 670 questionnaires were distributed to undergraduate students from the Wuhan University Medical College. The main categories involved the evaluation of practicability, students' support and satisfaction for innovative education reform.

Results: Most students have high support for scientific research innovation. Totally $92.5 \%$ of the students believe teachers' guidance is important for conducting scientific research. Only $40 \%$ of students believe that they can get information about innovation activities. About $60.64 \%$ of students think the basic knowledge of books can't meet their learning requirements and $83.62 \%$ students think it is necessary for the school to set up research and training courses. Setting up problem discussion classes $(65 \%)$ and teachers' teaching attitude and methods (70\%) are most satisfied, followed by academic lectures (53\%). Less than half of the students are satisfied with the undergraduate tutorial system (49\%), the experimental facilities provided by the school (46.5\%), and innovative atmosphere (39\%). The evaluation of students' own scientific research innovation ability is also not very high (12.31\%).

Conclusions: Scientific research training plays an important role in the cultivation of college students' scientific research and innovation ability, and teachers play a leading role. Undergraduate tutorial system, opening laboratory and the other managements contribute to innovative education. However, in the process of implementation, some problems still need to be continuously improved.

\section{Introduction}

Higher education is the key to cultivate outstanding talents [1]. Since the founding of People's Republic of China, our country gradually began to establish modern medical education system by learning advanced educational experience and combing with the social status of China.[2] After decades of exploration and development, new medical education system with Chinese characteristics has been formed.[3, 4] However, results are far from satisfaction. Both domestic and foreign educational circles hold the view that it is in great need to carry out innovation education and improve the deficiency of the existing education system.[5, 6]

Along with the increase of the Chinese health security requirements, clinicians, as an important part of the medical service system, must be very professional.[7] In addition to mastering theoretical knowledge, medical students should also possess research innovation ability to cope with the fierce competition in the future.[8] It is an essential component of modern undergraduate medical education to cultivate students' positive attitude towards scientific research.[9] To meet China's growing need for high-quality medical doctors, medical education reform appears to be inevitable.[10-12] On July 11, 2017, a bold plan to revolutionize medical education have already issued by the State Council of China.[13] Incorporating 
scientific research into medical undergraduate courses is highly appreciated and will certainly facilitate future research undertakings. [14] Furthermore, if good foundation in the undergraduate stage is laid, scientific research innovation will have a qualitative leap in the graduate stage.

The implementation of education reform is the key measure to improve the innovation ability of undergraduates.[15] In 2008, Wuhan University Medical School in China proposed to reform its curriculum by adapting the curriculum of University of Chicago Medical School. The reform was generally well received, greatly appreciated by participants, and had a positive impact on students.[16] To fit with the rapid development of medical technology and medicine industry, we also carried out medical undergraduate tutorial system, opened university laboratory and held academic lectures to cultivate the scientific research and innovation ability of undergraduates. Our study briefly evaluated the status of innovation education reform in Wuhan University Medical School, and discussed some possible ways to solve the current problems.

\section{Methods}

This report focuses on the practice of Innovation Education Reform in Wuhan University Medical College. The main categories of the questionnaire items involved the evaluation of practicability, students' support and satisfaction for innovative education reform.

Based on literature review as well as our reforms and goals regarding the new medical reform, a first draft of a questionnaire was created and then was distributed to faculty and relevant administrators at Wuhan University Medical School to revise the questionnaire appropriately. The revised version was then taken to three medical educators for verification of its reliability and validity to assess the scientific innovation education reform. Finally, a third version containing 14 items was created after a thorough analysis and integration of feedback provided by the medical educators. Specific items are shown in Table1. 
Table 1

Questionnaire survey items of innovation education reform practice in Wuhan University Medical College

\section{Support items}

1. You think strengthening scientific research and innovation training is helpful to cultivate innovation ability.

2. Scientific research innovation experiment is important to undergraduate students.

3. You hope to have an advantage in scholarship selection through scientific research and innovation practice.

4. The cultivation of scientific research innovation ability for undergraduate is helpful to the postgraduate recommendation.

5. Scientific research innovation experiment is helpful for the understanding and consolidation of professional knowledge.

6. You think that the guidance of teachers counts a great deal for engaging in scientific research experiments.

7. You can get information about scientific research and innovation activities from all sources.

8. You want a teacher to guide you to determine your research direction and goals.

9. You want to have more opportunities to exercise on your own initiative in the learning process.

10. You think that under the guidance of the teacher, your innovation consciousness can be greatly improved.

Satisfaction items

1. Setting up a problem discussion course in the course study.

2. The atmosphere of Scientific Research Innovation created by Schools.

3. Various academic lectures conducted by the school.

4. Teachers' teaching attitude and teaching methods.

5. Class tutors and candlelight tutors scheduled. (Namely undergraduate tutorial system)

6. The hardware facilities provided by the school for students to engage in scientific research experiments.

7.Your current practical ability of scientific research and innovation

8. The current courses are enough for your basic research skills.

9. The basic knowledge of books that can't meet your learning requirements.

10.The necessity for the school to set up research and training courses.

The questionnaires were Likert-scale-type questions for measuring students' support and the answers were divided into 5 categories: unsupportive or dissatisfy, borderline, somewhat supportive or satisfy, strongly supportive or satisfy, unclear. "Borderline" represents "neither supportive nor unsupportive" or 
"neither satisfied nor dissatisfied". "Somewhat supportive or satisfy" and "strongly supportive or satisfy" ratings are combined into supportive or satisfy, while the others items remain the same in order to obtain the frequency distribution of each variable. The 670 questionnaires were distributed and direct interviews were conducted. All the participants in this survey were undergraduates from the Medical School of Wuhan University. The percentages ranged from grades are $6.1 \%$ (grade 1), 16.9\% (grade 2), $22.3 \%$ (grade 3 ), $34.5 \%$ (grade 4 ), and $20.2 \%$ (grade 5 ). Informed consent was provided to all the participants and signed prior to beginning the study. Our research was approved by ethics committee of Zhongnan hospital of Wuhan University. All methods were performed in accordance with the Declaration of Helsinki.

\section{Results}

All 670 questionnaires were recycled and analyzed together. As shown in Figure 1, the majority of students have high support for scientific research innovation (Item 1 to Item 5 ). About $90.5 \%$ of students believe that it is very important for college students to participate in scientific research and innovation activities. Most students believe that through scientific research and innovation practice, it provides advantages in the scholarship evaluation (73.87\%), contributes to the postgraduate recommendation (76.5\%), enhances the understanding and consolidation of professional knowledge (75\%), and helps to cultivate innovative ability (83\%). According to the analysis of practicability factors, "the guidance of teachers is very important to scientific research" achieves the highest support of $92.5 \%$. About $83.62 \%$ of students think that under the guidance of the teacher, their innovation consciousness can be greatly improved, and $86.6 \%$ students think they need a teacher to guide them to determine the research direction and goals. Generally, $83.19 \%$ students want to have more opportunities to exercise on their own initiative in learning, but only $40 \%$ of students believe that they can get information about research and innovation activities from multiple sources.

The results of the satisfaction survey on scientific research innovation are shown in Figure 2. According to the exhibiting answers, students' overall satisfaction with innovation reform is not very high. Totally, $83.62 \%$ students think it is necessary for the school to set up research and training courses. Setting up problem discussion courses (65\%) and teaching attitudes and methods of the teachers (70\%) are the most satisfactory items. About $53 \%$ of students are satisfied with the various academic lectures conducted by the school, and $67.66 \%$ of students believe that the current curriculum is sufficient for their basic research skills. However, $60.64 \%$ of students think the basic knowledge of books can't meet their learning requirements. Less than half of students are satisfied with the undergraduate tutorial system (49\%), the experimental hardware facilities provided by the school for students (46.5\%), and the innovative atmosphere of the school (39\%). The most dissatisfied category of the students are their own scientific research and innovation practice ability, with a satisfaction rate of $12.31 \%$.

\section{Discussion}

Since the year 2008, the Medical School of Wuhan University has proposed the reform of its curriculum. The innovation reform system has gradually become more and more consummate. Our questionnaire 
has shown that the majority of students have high support for scientific research innovation and believe it will provide advantages in the scholarship evaluation, contribute to the postgraduate recommendation, and enhance the understanding of professional knowledge. For satisfaction surveys, the overall satisfaction is not very high. Only $12.31 \%$ of the students are satisfied with their own current practical ability of scientific research innovation, and on the contrary, more than $40 \%$ of the students are dissatisfied. There are still about half of the students who are not aware of their current ability of scientific research and innovation. Surveys have produced results essentially in agreement with our above conclusion $[17,18]$ that the students do not realize the importance of scientific research and their lack of awareness and interest in innovation may be the reasons of low innovation satisfaction[19]. In our questionnaire survey, $92.5 \%$ of the students think tutors' guidance count a great deal for scientific research innovation.

The tutor plays an important role in guiding students to develop frameworks for use in the construction of knowledge[20]. Studies have shown that tutors have equally competent teaching skills as the experienced medical teachers, and the trained mentors were considered to have a more positive role for students than untrained mentors.[21, 22] Consequently, undergraduate tutorial system, which is originated from University of Oxford in nineteenth century,[23] has become a new educational management system in colleges. Several studies indicate that innovative talents can be cultivated via tutorial system whose goal is to motivate students' enthusiasm, enhance the students' scientific research abilities, and especially cultivate innovative abilities.[19, 24-27] Undergraduate tutorial system was implemented in Wuhan University Medical School since 2008. Through years of hard work, it has been almost mature and presented its diversity. However, less than half of the students are satisfied with the current tutorial system based on present study. We must admit that there are still some problems in actual implementation process not only in Wuhan University, but also in other colleges and universities, which is limited by various objective conditions probably mainly caused by two aspects: school and tutors. Here, we will discuss the problems in details and elucidate some possible solutions.

For the clinical doctors, the clinical affairs of patients often come first, followed by researches and papers, which are often key points for doctors' promotion and tenure assessment so teaching is often placed in the least valued position [28]. To solve these problems, the college should perfect requirements and evaluation criteria for tutors and take the guidance work of undergraduate tutors as an important evaluation basis for their annual assessment, recognition and promotion. Besides, the university could organize excellent undergraduate tutor elections each year, and give recognition and reward to tutors with special outstanding work performance. For tutors, a relative perfect undergraduate tutorial system running process is needed. Firstly, tutors help students to establish a proper outlook on university study and scientific research through weekly meeting. Secondly, tutors guide undergraduates to read paper and write reviews about what they are interested, because reading enough researches and reviews is of great importance at the beginning [29]. Thirdly, the tutors can direct the students to go into the laboratory to learn technology and design personal project at the junior years. Given to the convenience of WeChat, students and tutors can also communicate with each other immediately no matter what problems they meet. The detailed process is shown in Figure 3. In addition, setting up of problem discussion classes, 
such as PBL (problem-based learning) in the course learning is widely accepted by students with dissatisfaction of only $7 \%$, which should be maintained to mobilize students' enthusiasm. Furthermore, strengthening the training of tutors and promoting communication among peer tutors is helpful for tutors to better guide students as described above, which should be included in the implementation of tutor system.

In this questionnaire, we also observe that more than three quarters of students hope to enhance their understanding and consolidation of professional knowledge through scientific research innovation experiment. Experimental teaching and training of medical undergraduates is an important way to cultivate students' scientific research innovation ability and then to cultivate innovative talents, because the experiment is the key point of the implementation of the innovative ideas.[30, 31] In recent years, many tutors open their laboratories, and encourage students to enter the laboratory to participate in scientific research.[32-34] In the medical school of Wuhan University, the undergraduate students will go to the laboratories they are interested in and finish some basal experiments supported by experienced postgraduates. Moreover, owing to the opening of university laboratories, an increasing number of undergraduates got the program supported by Wuhan University College Students Innovation Practice Center. However, students' satisfaction with the hardware facilities provided by the school for students to engage in scientific research experiments is not particularly high, with a satisfaction rate of $46.5 \%$.

To settle the problems, the college can improve the construction of laboratory and expand the existing experimental resources to meet the needs of both postgraduates and undergraduates. The opening of university laboratories should also be used reasonably. A standard management system must be established, including laboratory safety system, work discipline, environmental health and the institution for the use of experimental instrument. The tutors should also encourage the undergraduates to do scientific research actively, at the same time, they should pay more attention to guide undergraduates how to make experiments plan, improve the experimental design and analyze experimental data.

Good innovation environment is the basis and guarantee of innovation practice and make it easier for students to access information on innovative activities. Both tutorial system and opening of laboratories are indispensable for innovation, which are effective approaches to create innovative environment and cultivate innovative talents[35]. Schools should actively create scientific research innovation atmosphere, enable teachers to play a key guiding role and strengthen the management of scientific research processes, so that the undergraduates can feel the charm of scientific research, then to tap their greatest potential for innovation. Schools are also suggested to organize as many meaningful academic lectures as possible, because $53 \%$ of the students are satisfied with the academic lectures. The academic lecture topics should solicit students' opinions and meet the needs of students. For example, BBS (bulletin board system) as one of the forms, can supply an online bulletin for students to post their demands, their opinions and their points of interest, which can play a certain role in improving the atmosphere of scientific research.

\section{Conclusions}


Through innovative education reform, the majority of students have high support of scientific research innovation. However, students' satisfaction with innovation reform is not very high especially with the dissatisfying innovative atmosphere provided by the school, which lead to some students unable to have access to information about innovative activities. Undergraduate tutorial system and opening laboratory are vital in improving the scientific research innovation and create innovative atmosphere, but there are still some problems in the actual implementation process. We put forward some solutions to solve above problems in this study. Besides, academic lectures and the teaching form of problem discussion courses also have positive impacts on innovative education, which are suggested to be maintained and strengthened. In a word, scientific research innovation education for undergraduates is a process of continuous learning, research, reflection and enhancement, which needs us to keep exploring.

\section{Abbreviations}

PBL: problem-based learning; BBS: bulletin board system.

\section{Declarations}

\section{Competing interests}

No potential conflict of interest was reported by the authors.

\section{Ethics approval and consent to participate}

Before our study started, informed consent was provided to all the participants and signed prior to beginning the study. Our research was approved by ethics committee of Zhongnan hospital of Wuhan University.

\section{Consent for publication}

Not applicable

\section{Availability of data and materials}

The datasets generated and analyzed during the current study are not publicly available due to the further study we are now investigating and the questionnaires and the raw data will be used but they are available from the corresponding author (Prof. Fuling Zhou) on reasonable request.

\section{Funding}


This work was supported by the Teaching Reform Project of Wuhan University from China under Grant (303-413200007), the Chinese Society of Academic Degrees and Graduate Education (B3-YX2018030221), Wuhan University Graduate Tutor Education Innovation Project (201942) and Wuhan University Medical Science Department Teaching Research Project (2019056).

\section{Authors' contributions}

FLZ and YFY designed the study and the questionnaires. XZ and PL collected the information, analyzed the data and wrote the article. HRW and HS recruited the participants and performed the study. All authors reviewed the manuscript.

\section{Acknowledgements}

The author thanks Y.W. Wu's assistance in the early stage of data collection.

\section{References}

1. Schneider M, Preckel F: Variables associated with achievement in higher education: A systematic review of meta-analyses. Psychological bulletin 2017, 143(6):565-600.

2. Ban N: [The current status of undergraduate medical education. 4. Recent trends in the National Examination for Medical Practitioners]. Nihon Naika Gakkai Zasshi 2007, 96(12):2673-2680.

3. Gao T, Shiwaku K, Fukushima T, Isobe A, Yamane Y: Medical education in China for the 21 st century. Med Educ 1999, 33(10):768-773.

4. Schwarz MR, Wojtczak A, Zhou T: Medical education in China's leading medical schools. Med Teach 2004, 26(3):215-222.

5. Kozu T: Medical education in Japan. Acad Med 2006, 81(12):1069-1075.

6. Zhang Q, Lee L, Gruppen LD, Ba D: Medical education: changes and perspectives. Med Teach 2013, 35(8):621-627.

7. Hou J, Michaud C, Li Z, Dong Z, Sun B, Zhang J, Cao D, Wan X, Zeng C, Wei B et al: Transformation of the education of health professionals in China: progress and challenges. Lancet 2014, 384(9945):819-827.

8. Van Dyke AR, Gatazka DH, Hanania MM: Innovations in Undergraduate Chemical Biology Education. ACS Chem Biol 2017.

9. Hren D, Lukic IK, Marusic A, Vodopivec I, Vujaklija A, Hrabak M, Marusic M: Teaching research methodology in medical schools: students' attitudes towards and knowledge about science. Medical education 2004, 38(1):81-86.

10. Huang L, Cheng L, Cai Q, Kosik RO, Huang Y, Zhao X, Xu GT, Su TP, Chiu AW, Fan AP: Curriculum reform at Chinese medical schools: what have we learned? Medical teacher 2014, 36(12):1043- 
1050.

11. Emanuel EJ: Reforming American Medical Education. The Milbank quarterly 2017, 95(4):692-697.

12. Hays R: Including health promotion and illness prevention in medical education: a progress report. Med Educ 2018, 52(1):68-77.

13. Song P, Jin C, Tang W: New medical education reform in China: Towards healthy China 2030. Bioscience trends 2017, 11(4):366-369.

14. Abu-Zaid A, Alkattan K: Integration of scientific research training into undergraduate medical education: a reminder call. Medical education online 2013, 18:22832.

15. Nara N, Suzuki T, Tohda S: The current medical education system in the world. Journal of medical and dental sciences 2011, 58(2):79-83.

16. Sherer R, Dong H, Yunfeng Z, Stern S, Jiong Y, Matlin K, Baoping Y, Husain AN, Morgan I, Cooper B et al: Medical education reform in wuhan university, china: a preliminary report of an international collaboration. Teaching and learning in medicine 2013, 25(2):148-154.

17. Ellis JS, Hobson RS, Waterhouse PJ, Meechan JG, Hogg SD, Whitworth JM, Thomason JM: Tutor perceptions of the use of a reflective portfolio within a pastoral tutor system to facilitate undergraduate personal development planning. European journal of dental education: official journal of the Association for Dental Education in Europe 2006, 10(4):217-225.

18. Driessen EW, van Tartwijk J, Overeem K, Vermunt JD, van der Vleuten CP: Conditions for successful reflective use of portfolios in undergraduate medical education. Medical education 2005, 39(12):1230-1235.

19. Ellis JR: The tutorial system in medical schools. Lancet 1956, 271(6939):375-378.

20. Chng E, Yew EH, Schmidt HG: Effects of tutor-related behaviours on the process of problem-based learning. Advances in health sciences education: theory and practice 2011, 16(4):491-503.

21. Horneffer A, Fassnacht U, Oechsner W, Huber-Lang M, Boeckers TM, Boeckers A: Effect of didactically qualified student tutors on their tutees' academic performance and tutor evaluation in the gross anatomy course. Annals of anatomy = Anatomischer Anzeiger: official organ of the Anatomische Gesellschaft 2016, 208:170-178.

22. Lauter J, Branchereau S, Herzog W, Bugaj TJ, Nikendei C: Tutor-led teaching of procedural skills in the skills lab: Complexity, relevance and teaching competence from the medical teacher, tutor and student perspective. Zeitschrift fur Evidenz, Fortbildung und Qualitat im Gesundheitswesen 2017, 122:54-60.

23. Goldbloom RB, Jones GM: The role of a tutorial system in undergraduate medical education. Can Med Assoc J 1967, 96(14):1027-1031.

24. Ishigooka J: [Undergraduate medical education in psychiatry by employing the tutorial system]. Seishin Shinkeigaku Zasshi 2009, 111(2):154-157.

25. St-Onge C, Frenette E, Cote DJ, De Champlain A: Multiple tutorial-based assessments: a generalizability study. BMC Med Educ 2014, 14:30. 
26. Melo L, Schrieber L, Eyles J, Deveza LA, Meneses SRF, Hunter DJ: Comparison of physical examination performance of medical students trained by musculoskeletal versus nonmusculoskeletal specialists. Int J Rheum Dis 2017, 20(4):451-459.

27. $\mathrm{S} \mathrm{JH}$ : The mentoring role of the personal tutor in the;Fitness for practice' curriculum: an all Wales approach. Nurse education in practice 2004, 4(4):271-278.

28. Samarasekera DD, Ooi S, Yeo SP, Hooi SC: Medical education in Singapore. Medical teacher 2015, 37(8):707-713.

29. Shanks JD, Izumi B, Sun C, Martin A, Byker Shanks C: Teaching Undergraduate Students to Visualize and Communicate Public Health Data with Infographics. Front Public Health 2017, 5:315.

30. Xing W, Mo M, Su H: An exploration for research-oriented teaching model in biology teaching. Yi chuan $=$ Hereditas 2014, 36(7):732-738.

31. Chen J, Zhou J, Sun L, Wu Q, Lu H, Tian J: A new approach for laboratory exercise of pathophysiology in China based on student-centered learning. Adv Physiol Educ 2015, 39(2):116119.

32. Gardner DL: The Open University: teaching laboratory medicine. J R Soc Med 1978, 71(5):373-375.

33. Nie M, Gao ZY, Wu XY, Jiang CX, Du JH: Evaluation of oral microbiology lab curriculum reform. BMC Med Educ 2015, 15:217.

34. Spencer AL, Brosenitsch T, Levine AS, Kanter SL: Back to the basic sciences: an innovative approach to teaching senior medical students how best to integrate basic science and clinical medicine. Acad Med 2008, 83(7):662-669.

35. Johnsen $\mathrm{H}$ : Learning to create new solutions together: A focus group study exploring interprofessional innovation in midwifery education. Nurse Educ Pract 2016, 16(1):298-304.

\section{Figures}




\section{Support results}

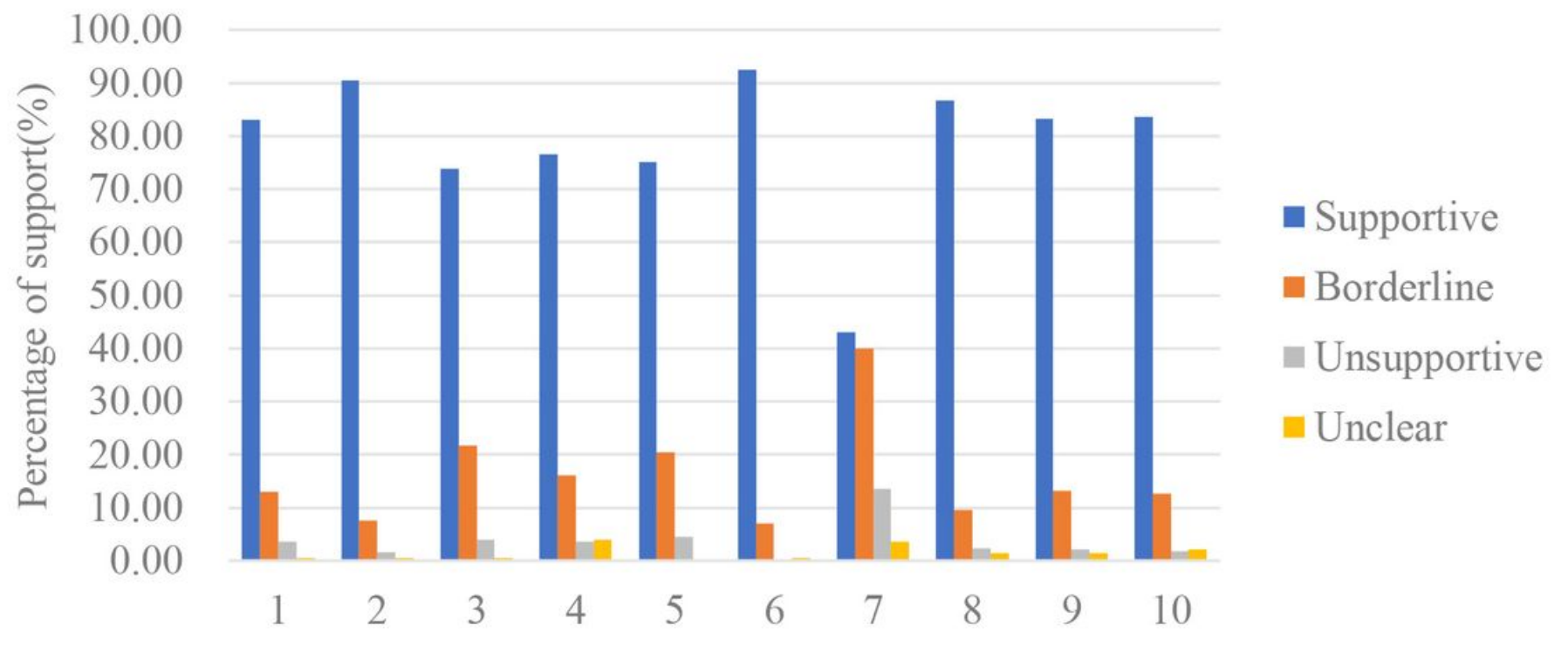

\section{Figure 1}

Items evaluating the support of scientific research innovation education reform: Percentage of students reporting Supportive, Borderline, Unsupportive or Unclear with given statements.

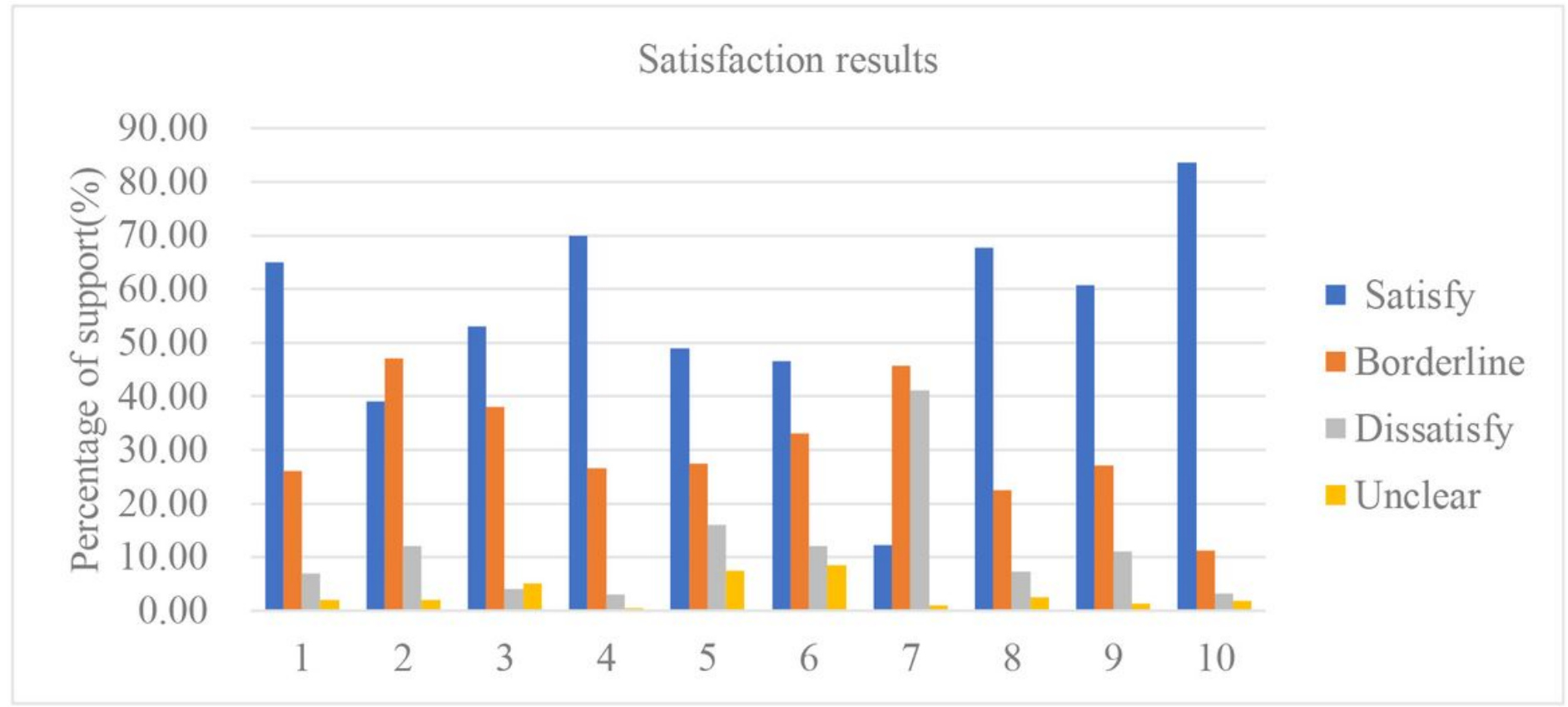

Figure 2

Items evaluating the satisfaction of scientific research innovation education reform: Percentage of students reporting Satisfy, Borderline, Dissatisfy, or Unclear with given statements. 


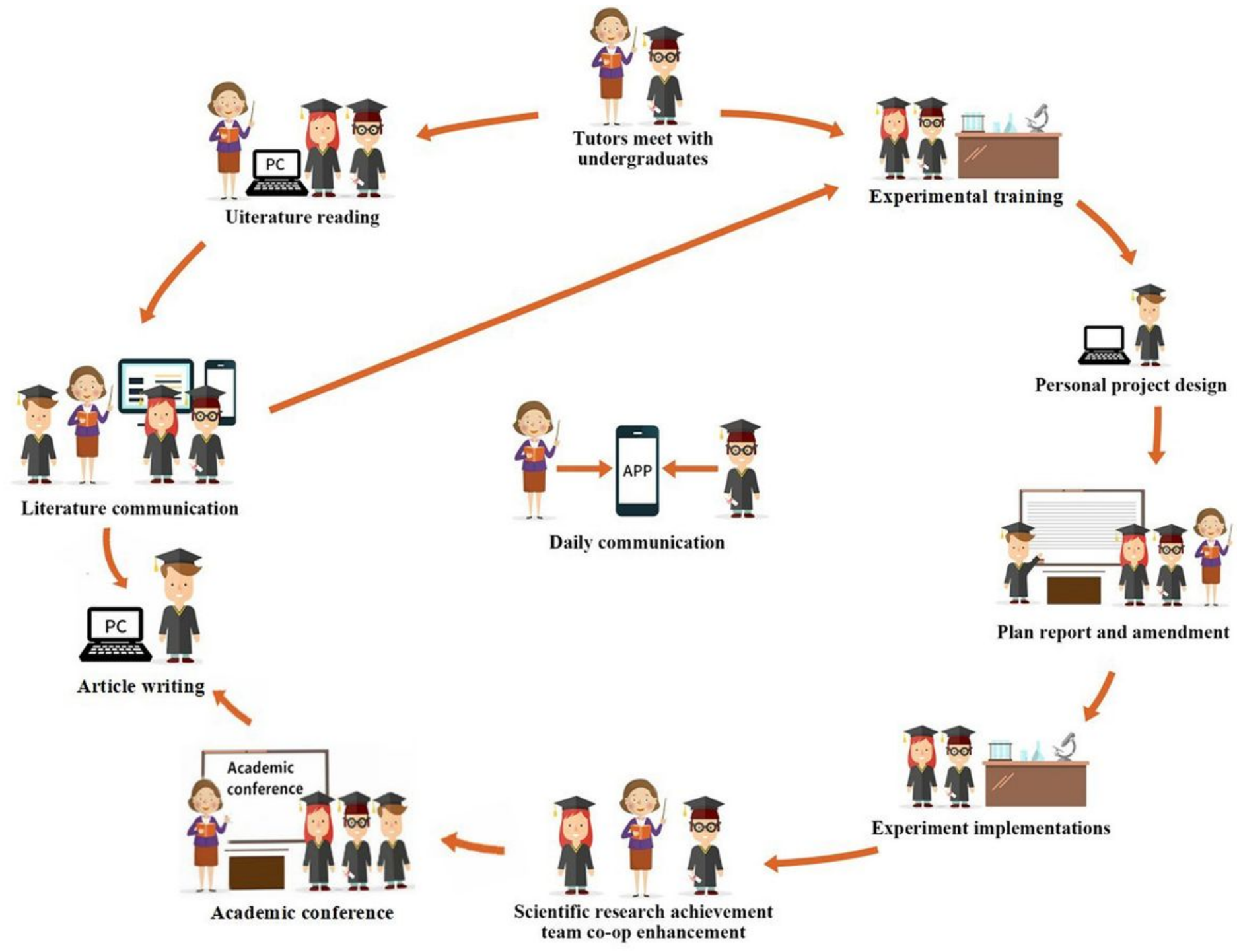

Figure 3

Improved undergraduate tutorial system running process. 